\title{
A study on dynamic modulus of self-consolidating rubberized concrete
}

\author{
Mehmet Emiroğlu ${ }^{* 1}$, Servet Yildiz ${ }^{2 a}$ and M. Halidun Keleştemur ${ }^{3 b}$ \\ ${ }^{1}$ Department of Civil Engineering, Düzce University Technology, Düzce, Turkey \\ ${ }^{2}$ Department of Civil Engineering, Firat University Technology, Elazığ, Turkey \\ ${ }^{3}$ School of Engineering Department of Mechanical Engineering, Meliksah University, Kayseri, Turkey
}

(Received August 21, 2014, Revised February 15, 2015, Accepted February 21, 2015)

\begin{abstract}
In this study, dynamic modulus of elasticity of self-consolidating rubberized concrete is evaluated by using results of ultrasonic pulse velocity and resonance frequency tests. Additionally, correlation between dynamic modulus of elasticity and compressive strength results is compared. For evaluating the dynamic modulus of elasticity of self-consolidating rubberized concrete, prismatic specimens having $100 \times 100 \times 500 \mathrm{~mm}$ dimensions are prepared. Dynamic modulus of elasticity values obtained by non-destructive measurements techniques are well agreed with those given in the literature.
\end{abstract}

Keywords: rubberized concrete; ultrasonic measurement; resonance frequency; dynamic modulus

\section{Introduction}

The main problem of rubberized concrete is addressed to poor bond mechanism between tire particles and cement paste. Therefore, mechanical properties and elastic modulus of rubberized concrete gradually decrease with the addition of rubber particles into the mixture. One of the suggestions to improve the mortar phase is to enhance a strong bonding between rubber particles and cement paste (Eldin 1993, Topçu 1995, Khatib and Bayomy 1999, Güneyisi et al. 2004, Emiroglu et al. 2008, Aiello and Leuzzi 2010, Emiroglu et al. 2012). It is well known that self-consolidating concrete has denser mortar phase than that of conventional concrete, and various filler materials used to improve rheology, strength and durability of concrete and, reduce cement content (Okamura and Ouchi 2003, Bartos 2005, EFNARC 2005). There are several successful examples of rubberized concrete applications which have been obtained by using different mixing ratios. (Bignozzi and Sandrolini 2006) used CEM II/A-LL R 42.5 R cement and calcium carbonate as filler material in their experiments and compared the self-consolidating mixtures with and without rubber particles. It is reported that a strong adhesion between tire rubber and cement matrix is obtained and it is verified by scanning electron microscopy examination on the undisturbed fracture surface resulting from compressive loading. (Turatsinze and Garros 2008) are

*Corresponding author, Dr., E-mail: mehmetemiroglu@duzce.edu.tr

a Associate Professor, E-mail: syildiz@firat.edu.tr

${ }^{\mathrm{b}}$ Professor, E-mail: hkelestemur@gmail.com 


\section{Mehmet Emiroğlu, Servet Yildiz and M. Halidun Keleştemur}

used binder including CEM I $52.5 \mathrm{R}$ cement and calcareous filler materials to produce self-consolidating rubberized concrete. They reported that incorporation of rubber aggregate improves the strain capacity of SCC before macro-crack localization. (Najim and Hall 2012) evaluated CEM I 52.5 cement and pulverized Fuel Ash as filler materials in their experiments and they have reached up to $54 \mathrm{MPa}$ for compressive strength. Additionally, there are numerous experimental studies performed about rubberized concrete since 1990s. Up to now, issues on the studies about rubberized concrete are still promising subject. It is consensually accepted that rubber aggregate can improve concrete ductility and resist to the vibration loads in the structures and help to damp it. One of the basic reasons on the investigations of rubberized tire is to maintain recycling opportunity of waste tires by using it in a structural application (Topçu 1995, Khatib and Bayomy 1999, Emiroglu et al. 2012).

Most of the concrete structures such as roads, sidewalks, sport courts, dams, barriers, road foundations, and other infrastructural facilities etc. subject to alternating loads such as impact loading or dynamic shock of moving vehicles, and it is recommended that rubberized concrete can be used in the structures subjected to cyclic loadings (Khatib and Bayomy 1999, Zheng et al. 2008). Dynamic performance of the concrete structures subjected to cyclic loadings can be determined by using one of non-destructive test procedures. Ultrasonic pulse velocity and resonance frequency tests are well known methods to evaluate the dynamic modulus of elasticity of concrete specimens (Malhotra and Carino 2004). The term of "dynamic properties of concrete" contains the dynamic modulus of elasticity, natural resonance and vibration damping ratio. These are interacted with each other and they are important in structural applications, particularly concerning to vibration control and noise reduction. Dynamic modulus of elasticity can provide a reliable guide to understand the dynamic response behavior of the material while damping is a material property characteristic of energy dissipation that can be identified in the form of the decay of free vibration. Optimization of these properties can significantly increase structural reliability in cases of earthquakes, accidental loading and hydrostatic and wind loading, or explosive blasts and crashing (Zheng et al. 2008, Najim and Hall 2012).

Natural frequency of vibration is a well-known dynamic property of any elastic system. The natural frequency of vibration for a vibrating beam is mainly related to the dynamic modulus of elasticity and density of the material. Thus, the dynamic modulus of elasticity of a material can be determined from the measurement of the natural frequency of vibration of prismatic bars and the mathematical relationships available between the two. These relationships are derived for the solid media considered to be homogeneous, isotropic, and perfectly elastic, but they may be applied to heterogeneous systems, such as concrete, when the dimensions of the specimens are large in relation to the size of the constituents of the material (Malhotra and Carino 2004). The relationship between pulse velocity and dynamic elastic modulus of the composite material measured by resonance tests on prisms is fairly reliable (Bungey and Millard 2010). The behavior of concrete under dynamic actions is determined by its dynamic properties (such as dynamic modulus of elasticity, modulus of rigidity, Poisson's ratio, compressive strength or strain limits), which present different values compared to their static counterparts. The dynamic performance of a structure is also highly conditioned by its damping ability. In a vibrating structure, damping is understood as the dissipation of the mechanical energy, generally by converting it into thermal energy (Giner et al. 2011). Ultrasonic pulse velocity (UPV) testing is a preferred nondestructive method that can be used to determine the elastic properties of concrete (Hassan and Jones 2012). And the other test method is resonance frequency to determine dynamic modulus of elasticity. Resonance frequency testing is an alternative to the UPV method. This method has been used to determine the elastic 
modulus of normal concrete, unlike the UPV, is applied only to the laboratory specimens rather than in situ structural members. The size and shape of specimens are limited to standard cylinders and prisms (Hassan and Jones 2012).

In this study, dynamic modulus of elasticity of self-consolidating rubberized concrete were evaluated using ultrasonic pulse velocity and resonance frequency tests results. Also, correlation between dynamic modulus of elasticity and compressive strength results is compared.

\section{Materials and method}

\subsection{Material}

The raw materials, CEM I 42.5 R and CEM IV/B (P) type cement, granulated blast furnace slag, 0-5 $\mathrm{mm}$ and 5-12 $\mathrm{mm}$ natural aggregate, water, superplasticizer, air entraining agent and waste tire rubbers are the main components of the Rubberized Self-Consolidating Concrete (RSCC). The cement which is used in the mixture is compatible with the National Standard, TS EN 197-1:2002. Granulated blast furnace slag is also used for the filler material in the mixture. CEM I $42.5 \mathrm{R}$, Cem IV/B (P) and granulated blast furnace slag are provided from a local supplier, Oyak Bolu Cement Plant and their specific surface areas (Blaine) are 4209, 5649 and $5048 \mathrm{~cm}^{2} / \mathrm{g}$, respectively. And also superplasticizer and air entraining agent are supplied from Iksa Construction Chemicals in Turkey. Density of superplasticizer and air entraining agent are $1.10 \pm 0.03 \mathrm{~kg} / \mathrm{L}$ and $1.10 \pm 0.02$ $\mathrm{kg} / \mathrm{L}$ respectively.

Waste tire rubbers are chopped by mechanical cutting process and then fine particles which are not wanted in the mixture are removed by sieving method using $4.75 \mathrm{~mm}$ sieve. Fiber shaped rubbers used in this study are named Tire Fibers (TF)

Fig. 1 shows the fiber shaped view and rough surface of TF used in the mixture. Specific gravities of natural fine $(0-5 \mathrm{~mm})$, coarse aggregate $(5-12 \mathrm{~mm})$ and the TF were $2.75,2.79$ and 0.91 , respectively. Polycar 300 and Iksaaer trade mark superplasticizer and air entraining agent were provided from Iksa Construction Chemicals Company in Turkey.

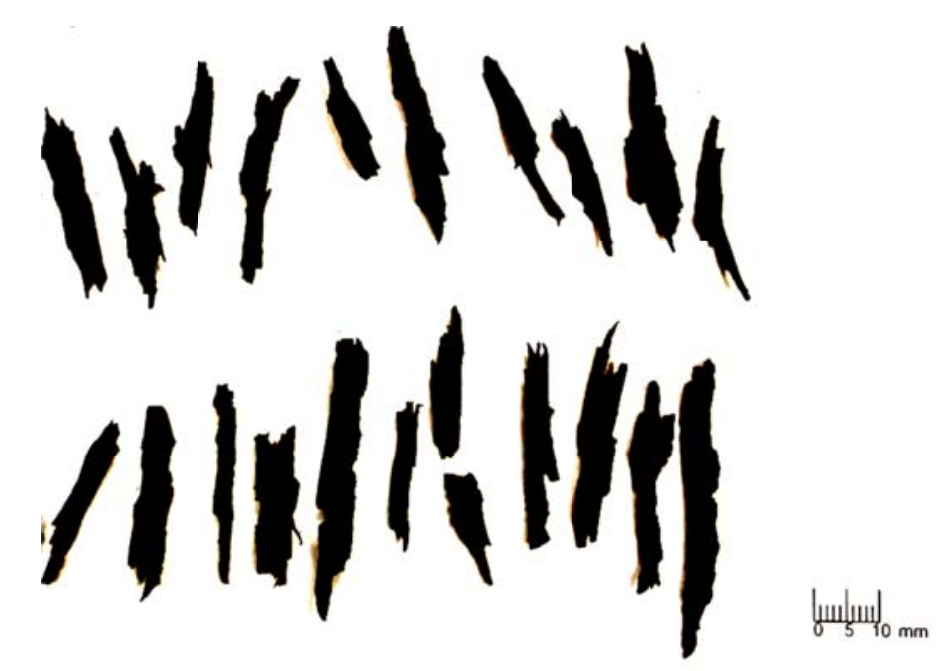

Fig. 1 Fiber shaped tire rubbers (TF) 


\subsection{Method}

Table 1 RSCC mix design $\left(1 \mathrm{~m}^{3}\right)$

\begin{tabular}{|c|c|c|c|c|c|}
\hline \multirow{3}{*}{ Constituents } & \multicolumn{5}{|c|}{ SCC Codes - TF Content } \\
\hline & R0 & $\mathrm{R} 15$ & $\mathrm{R} 30$ & $\mathrm{R} 45$ & R60 \\
\hline & 0 & 15 & 30 & 45 & 60 \\
\hline Cem I $\left(\mathrm{kg} / \mathrm{m}^{3}\right)$ & 300 & 300 & 300 & 300 & 300 \\
\hline Cem IV/B (P) $\left(\mathrm{kg} / \mathrm{m}^{3}\right)$ & 165 & 165 & 165 & 165 & 165 \\
\hline Slag $\left(\mathrm{kg} / \mathrm{m}^{3}\right)$ & 135 & 135 & 135 & 135 & 135 \\
\hline Total Filler $\left(\mathrm{kg} / \mathrm{m}^{3}\right)$ & 600 & 600 & 600 & 600 & 600 \\
\hline Water $\left(\mathrm{kg} / \mathrm{m}^{3}\right)$ & 170 & 170 & 170 & 170 & 170 \\
\hline Water/Filler $\left(\mathrm{kg} / \mathrm{m}^{3}\right)$ & 0.28 & 0.28 & 0.28 & 0.28 & 0.28 \\
\hline Superplasticizer $(\% 1.5)\left(\mathrm{kg} / \mathrm{m}^{3}\right)$ & 9,00 & 9.00 & 9.00 & 9.00 & 9.00 \\
\hline Air entraining $(\% 0.5)\left(\mathrm{kg} / \mathrm{m}^{3}\right)$ & 3.00 & 3.00 & 3.00 & 3.00 & 3.00 \\
\hline Limestone Sand $(0-5 \mathrm{~mm})\left(\mathrm{kg} / \mathrm{m}^{3}\right)$ & 1192 & 1192 & 1192 & 1192 & 1192 \\
\hline Limestone Gravel (5-12 mm) $\left(\mathrm{kg} / \mathrm{m}^{3}\right)$ & 521 & 443 & 364 & 286 & 208 \\
\hline $\mathrm{TF}(\geq 5 \mathrm{~mm})\left(\mathrm{kg} / \mathrm{m}^{3}\right)$ & - & 26.6 & 53.2 & 79.9 & 106.5 \\
\hline Slump-flow (mm) & 840 & 775 & 725 & 643 & 615 \\
\hline Slump-flow $\mathrm{T}_{500}(\mathrm{sec})$ & 1.69 & 5.54 & 2.55 & 5.66 & 8.01 \\
\hline L-Box $\left(\mathrm{h}_{1} / \mathrm{h}_{2}\right.$ ratio $)$ & 1 & 1 & 1 & 0.38 & 0.5 \\
\hline V-Funnel (sec) & 11 & 17 & 23 & 41 & $\mathrm{~N}$ \\
\hline Fresh Concrete Unit Weight $\left(\mathrm{kg} / \mathrm{m}^{3}\right)$ & 2418 & 2319 & 2274 & 2205 & 1952 \\
\hline
\end{tabular}

Substitution of waste rubber with the natural aggregate by volume rate is a common method to produce the rubberized concrete and it is used in the earlier studies (Topçu 1995, Khatib and Bayomy 1999, Güneyisi, Gesoğlu et al. 2004, Emiroglu, Yildiz et al. 2008) as well as in this study. A plain (without TRA) SCC and four different R-SCC mixtures having 15\%, 30\%, $45 \%$ and $60 \%$ TRA replacement by volume of coarse aggregate are produced. Constituents of SCC with and without TRA are listed in Table 1.

Slump-flow, L-box, V-funnel, fresh concrete unit weight and hardened concrete compressive strength tests are performed on the concrete specimens. After the fresh concrete tests concrete samples were poured into the molds which are demoulded in a day following casting and then placed in a water tank for curing purpose and leaved there until the tests are done. $100 \times 100 \times 500$ $\mathrm{mm}$ prismatic and 100x100x100 mm cubic specimens are used for dynamic properties and compressive strength tests of RSCC. Six prismatic and four cubic samples were prepared for each concrete batch and all data are the mean values of these specimens. Prismatic specimens are tested for resonance frequency and ultrasonic pulse velocity (non-destructively) to evaluate the dynamic properties following 28 days of curing period.

Dynamic modulus of elasticity (Ed) of the materials can be calculated using Eq. (1) based on the UPV measurements (Malhotra and Carino 2004, Malhotra 2006 and ASTM C597-09). 


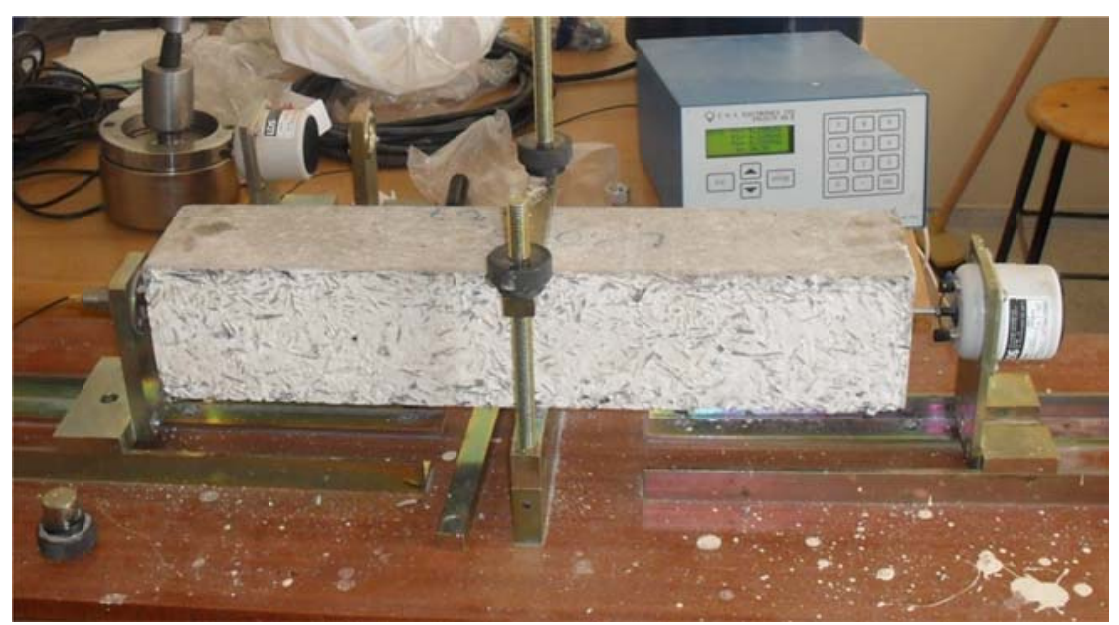

Fig. 2 Resonance frequency measurement on concrete

$$
\mathrm{E}_{d}=\mathrm{V}^{2} \rho \frac{(1+\mu)(1-2 \mu)}{(1-\mu)}
$$

Where, Ed is the dynamic modulus of elasticity (MPa), $\mathrm{V}$ is the ultrasound pulse velocity $(\mathrm{km} / \mathrm{sec}), \rho$ is the unit weight $\left(\mathrm{kg} / \mathrm{m}^{3}\right)$, and $\mu$ is the dynamic Poisson's ratio of the concrete specimen.

Dynamic modulus of elasticity values of all batches are calculated by using Eq. (2) after the resonance frequency measurement shown in Fig. 2 (Malhotra and Carino 2004, Malhotra 2006).

Where, Ed is the dynamic modulus of elasticity (MPa), L is the specimen length $(\mathrm{mm}), \rho$ is density $(\mathrm{kg} / \mathrm{m} 3)$ and $\mathrm{N}$ is the longitudinal resonance frequency of concrete $(\mathrm{kHz})$

$$
\mathrm{E}_{d}=4 \mathrm{~L}^{2} \rho \mathrm{N}^{2} \times 10^{-12}(M P a)
$$

\section{Results and discussions}

In the fresh state slump flow diameter of RSCC mix are affected from the TF content. With the increase in volume fraction of TF a decrease was observed in the slump flow diameter measurements. The flow of the mixes inhibited by the fiber shaped rubbers resulting from rough structure. On the contrary $\mathrm{T}_{500}$ measurements of the RSCC mixes are increased based on the TF content during the slump-flow test. These two values (slump-flow and $\mathrm{T}_{500}$ ) are also consistent with each other (Table 1). Viscosity class of R0, R15 and R30 series are determined as VS2/VF2 based on Efnarc 2005 guideline. At the higher value of $45 \%$ volume fraction of rubber, the flow is decreased and a blocking observed on the V-funnel gate (Table 1). As expected, fresh concrete unit weight of the RSCC mixes are decreased with increase of volume fraction of rubber substitution 
(Table 1). This is because of lighter density of rubber aggregates than the limestone aggregate. In the series of $\mathrm{R} 0$ and $\mathrm{R} 15 \mathrm{~h} 1 / \mathrm{h} 2$ ratio is observed as 1.00 . This is evidence of non-blocking is observed from the L-funnel test of the fresh mix. But the blocking is observed from the values of R30, R45 and R60 specimens (Table 1).

Table 2 shows descriptive statistics of the resonance frequency and ultrasonic pulse velocity values of RSCC specimens. Both resonance frequency and ultrasonic pulse velocity values slightly decrease with increasing rate of TF content in the RSCC.

The minimum compressive strength value is obtained from R60 specimens, while the maximum compressive strength is obtained from R0 (reference) specimens. Compressive strength values decrease from 71.61 MPa (reference specimen) to $25.20 \mathrm{MPa}$ (R60 specimen).

Table 2 Descriptive statistics of test results

\begin{tabular}{|c|c|c|c|c|c|c|c|}
\hline Test & $\mathbf{R}$ & $\mathbf{N}$ & Mean & Std. Deviation & Std. Error & Minimum & Maximum \\
\hline \multirow{5}{*}{$\begin{array}{c}\text { Compressive } \\
\text { Strength (MPa) }\end{array}$} & 0 & 4 & 71.61 & 4.74 & 2.37 & 67.52 & 78.45 \\
\hline & 15 & 4 & 63.69 & 3.05 & 1.52 & 60.45 & 67.81 \\
\hline & 30 & 4 & 47.16 & 8.39 & 4.19 & 41.81 & 59.67 \\
\hline & 45 & 4 & 32.88 & 4.82 & 2.41 & 29.68 & 40.06 \\
\hline & 60 & 4 & 25.24 & 2.46 & 1.23 & 21.83 & 27.53 \\
\hline \multirow{5}{*}{$\begin{array}{c}\text { Resonance } \\
\text { Frequency (Hz) }\end{array}$} & 0 & 6 & 3824.17 & 267.69 & 109.28 & 3555 & 4099 \\
\hline & 15 & 6 & 3662.00 & 296.88 & 121.20 & 3363 & 3950 \\
\hline & 30 & 6 & 3653.17 & 257.20 & 105.00 & 3395 & 3915 \\
\hline & 45 & 6 & 3363.00 & 212.57 & 86.78 & 3161 & 3650 \\
\hline & 60 & 6 & 3327.83 & 218.73 & 89.30 & 3054 & 3561 \\
\hline Ultrasonic Pulse & 0 & 4 & 5.07 & 0.02 & 0.01 & 5.04 & 5.09 \\
\hline Velocity & 15 & 4 & 4.90 & 0.04 & 0.02 & 4.85 & 4.93 \\
\hline (Cubic & 30 & 4 & 4.77 & 0.05 & 0.02 & 4.71 & 4.81 \\
\hline Specimens) & 45 & 4 & 4.52 & 0.06 & 0.03 & 4.45 & 4.57 \\
\hline (km/sec) & 60 & 4 & 4.35 & 0.05 & 0.03 & 4.27 & 4.40 \\
\hline Ultrasonic Pulse & 0 & 6 & 5.08 & 0.02 & 0.01 & 5.04 & 5.10 \\
\hline Velocity & 15 & 6 & 4.89 & 0.03 & 0.01 & 4.85 & 4.93 \\
\hline (Prismatic & 30 & 6 & 4.77 & 0.04 & 0.02 & 4.71 & 4.81 \\
\hline Specimens) & 45 & 6 & 4.50 & 0.06 & 0.02 & 4.45 & 4.57 \\
\hline (km/sec) & 60 & 6 & 4.35 & 0.04 & 0.02 & 4.27 & 4.40 \\
\hline
\end{tabular}


The reductions were encountered as $11.06 \%, 34.14 \%, 54.08 \%$ and $64.75 \%$ closely related with tire fiber replacement (R15, R30, R45 and R60). Ultrasonic pulse velocity of cubic and prismatic specimens has similar results, and standard deviation of both velocities is obtained close to zero.

Natural resonance frequency of the specimens range between 3327 to $3824 \mathrm{~Hz}$. Resonance frequencies values were decreased as in the case of compressive strength and ultrasonic pulse velocity measurements (Table 2 ).

Fig. 3 represents dynamic modulus of elasticity of RSCC specimens calculated by resonance frequency and ultrasonic pulse velocity values, respectively.

The results indicate that the nondestructive based calculation of the dynamic modulus of elasticity on the RSCC could be different. This may outcome from variation in results of ultrasonic pulse velocity based calculation which depends on empiric formulas such as Eq. (1). (Rahman et al. 2013) have reported that rubberized self-consolidating concrete mixtures show $10-20 \%$ lower dynamic modulus than that of plain SCC mixtures. Additionally, they reported that the rubber addition into concrete reduced the dynamic shear modulus (Rahman et al. 2013). Similar results have asserted by (Zheng et al. 2008) based on the normal vibrated rubberized concrete test results they examined (Malhotra and Carino 2004, Malhotra 2006, Zheng et al. 2008).

Fig. 4 demonstrates the comparison of calculated dynamic modulus of elasticity values obtained from two different non-destructive measurements (resonance frequency and ultrasonic pulse velocity). Relationship between dynamic modulus of elasticity values derived from these non-destructive test is expressed in Eq. (3). The determination coefficient of Eq. (3) is as high as 0.9795 for the empirical equation.

$$
\mathrm{E}_{d}(\text { Res. })=1.1967 \times\left(\mathrm{E}_{d}(\mathrm{UPV})\right)^{1.0262}
$$

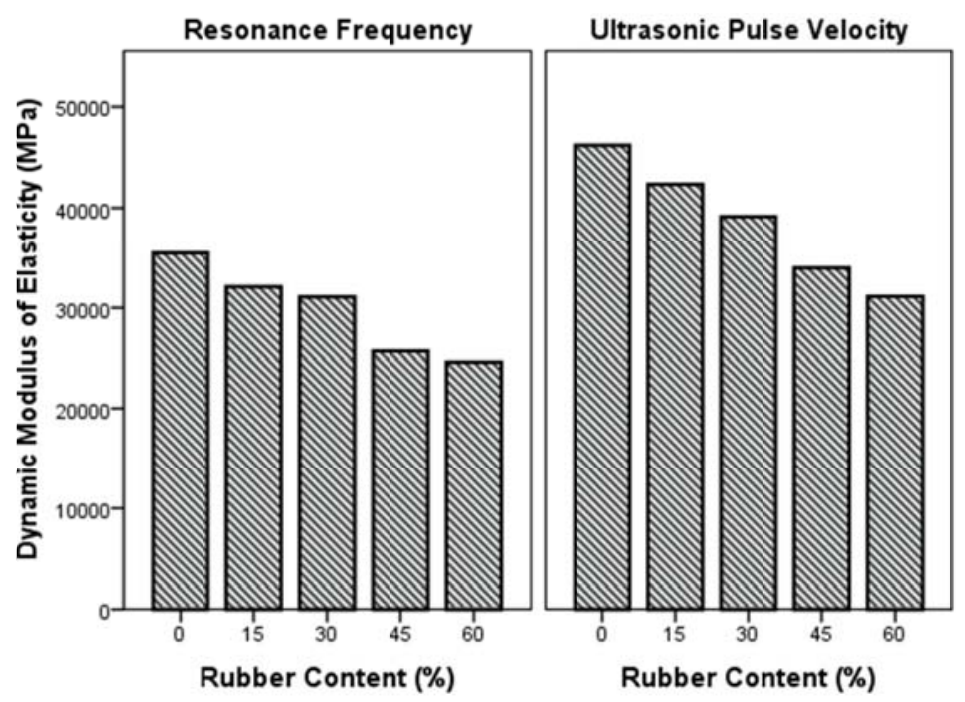

Fig. 3 Dynamic modulus of elasticity of RSCC via resonance frequency measurement 


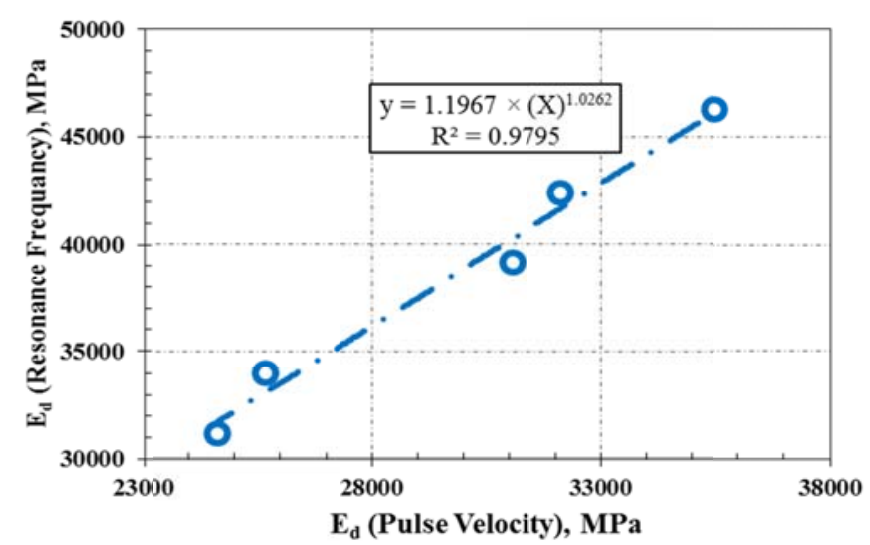

Fig. 4 Comparison of dynamic modulus of elasticity of RSCC specimens

Najim and Hall (2012) stated that, aggregate type and volumetric proportion are highly influential on the strength and elasticity. However, dynamic modulus is determined by using a non-destructive test with zero applied stress and hence there is neither micro crack formation nor creep during the test. In consequence, it appears higher than the static modulus of elasticity (secant) and it is almost equal to initial tangent modulus of elasticity, therefore dynamic moduli is significantly influenced by aggregate type and quantity (Najim and Hall 2012). Besides they have reported that dynamic moduli of RSCC mixes are found to decrease systematically with rubber content since the addition of crumb rubber causes significant air entrainment, and the rubber aggregates have a low elasticity than normal aggregate (Najim and Hall 2012).

Many times, poor bonding between rubber and cement past is addressed by the authors studied rubberized concrete and this situation is the cause of decrease in mechanical performance of the rubberized concrete. Fig. 5 demonstrates the decrease in compressive strength of RSCC specimens based on volume fraction of TF.

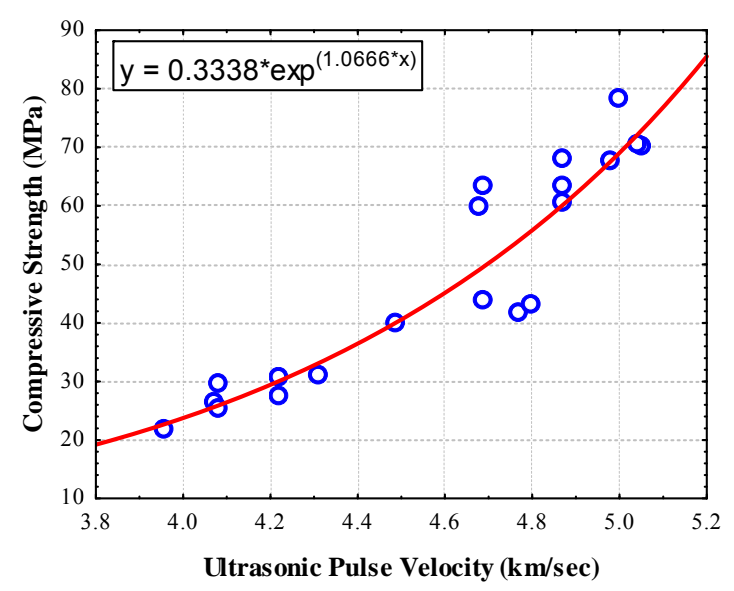

Fig. 5 Relationship between compressive strength and ultrasonic pulse velocity of RSCC 


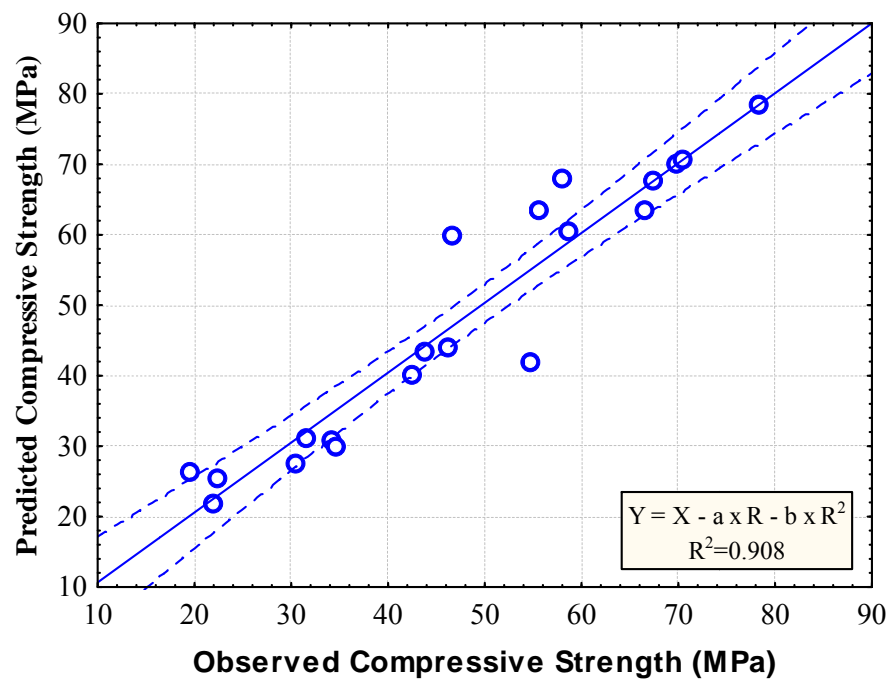

Fig. 6 Observed and predicted compressive strength values of the specimens

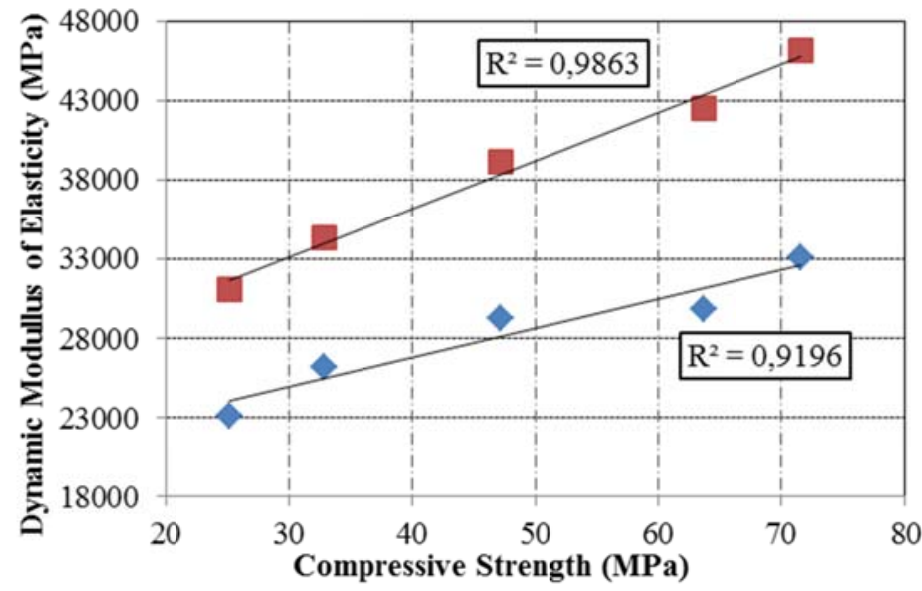

- Dynamic Modulus of Elasticity by Resonance Frequency

Dynamic Modulus of Elasticity by Pulse Velocity

Fig. 7 Relationships between dynamic modulus of elasticity and compressive strength

Higher the ultrasonic pulse velocity higher the compressive strength values are obtained based on the test results. Decline in compressive strength of RSCC mixes is directly originated from rubber aggregate replacement level $(\mathrm{R})$. This reduction in compressive strength can be predicted with a quadratic equation formulized in Eq. (4). 


$$
Y=X-a \times R-b \times R^{2}
$$

Where, $\mathrm{X}$ is compressive strength of reference specimen (R0), $\mathrm{Y}$ is compressive strength of rubberized concretes (R15, R30, R45 and R60) and a, b are function parameters obtained by regression analysis.

After the regression analysis, function parameters $(a, b)$ of quadratic equation in Eq. (4) is calculated as 0.783 and 0.0003 respectively. The coefficient of determination denoted $\mathrm{R}^{2}$ is 0.908 . Plot of observed versus predicted values based on the Eq.4 is drawn in Fig. 6.

The effect of compressive strength value of the RSCC specimens on dynamic modulus of elasticity is represented in Fig. 7. Highly correlated $\left(R^{2}=0.98633, R^{2}=0.9196\right)$ relationships are achieved between dynamic properties and compressive strength test results in the RSCC specimens.

\section{Conclusions}

Experiments have been performed to investigate the dynamic modulus of elasticity of rubberized self-compacting concrete based on non-destructive measurements. The following conclusions based on the results obtained in this investigation can be drawn;

It is possible to calculate modulus of elasticity of RSCC specimens via non-destructive test results. However, ignorable errors arising from the use of empirical formula can be met.

RSCC mixes have lower dynamic modulus of elasticity values than that of plain SCC and they are well consistent with the literature; (Zheng et al. 2008, Najim and Hall 2012, Rahman et al. 2013).

A very well defined relationship is observed at the values of dynamic modulus of elasticity both resonance frequency and ultrasonic pulse velocity measurements. The relationship confirms that the ultrasonic pulse velocity measurements can be used also for estimating the dynamic modulus of elasticity of rubber including self-consolidating concretes. Correlation coefficient of the relationships between two dynamic modulus of elasticity value is 0.9795 .

A relationship with a high correlation coefficient was determined between compressive strength and dynamic modulus of elasticity in the self-consolidating rubberized concrete mixes ( $\mathrm{R} 2=0.98633$ for UPV and R2 $=0.9196$ for resonance frequency measurements).

In order to determine the dynamic modulus of elasticity use of non-destructive tests (ultrasonic pulse velocity or resonance frequency) is very useful and simple method. And also they are suitable to deduce static modulus of elasticity of concrete. Examination of the effect of different curing times, and environmental conditions (such as high/low temperatures etc.) on dynamic properties of rubberized concrete is recommended. Besides damping ratio of rubberized concrete can have remarkable amount of importance in terms of dynamic characteristics of the structures in the future studies.

\section{Acknowledgements}

The research described in this paper was financially supported by the Scientific Research Projects Management Council of the Firat University of Turkey (Project no. 1933). 
A study on dynamic modulus of self-consolidating rubberized concrete

\section{References}

Aiello, M.A. and Leuzzi, F. (2010), "Waste tyre rubberized concrete: Properties at fresh and hardened state", Waste Manage, 30(8-9), 1696-1704.

ASTM Standard C597-09 (2003), Standard Test Method for Pulse Velocity Through Concrete, ASTM International, West Conshohocken, PA.

Bartos, P.J.M. (2005), “Testing-Scc: Towards New European Standards For Fresh SCC”, Proceedings of the 1st International Symposium on Design. Performance and Use of Self-Consolidating Concrete SCC2005. (Eds., Yu, Z., Shi, C., Khayat, K.H. and Xie, Y.).

Bignozzi, M.C. and Sandrolini, F. (2006), "Tyre rubber waste recycling in self-compacting concrete", Cement Concrete Res., 36(4), 735-739.

Bungey, J.H. and Millard, S.G. (2010), Testing of Concrete in Structures, Third Edition, Taylor \& Francis.

EFNARC (2005), The European Guidelines for Self-compacting Concrete: Specification, Production and Use.

Eldin, N.N. (1993), “Rubber tire particles as concrete aggregate”, J. Mater. Civ. Eng., 5(4), 478-496.

Emiroglu, M., Yildiz, S. and Kelestemur, M.H. (2008), "An investigation on its microstructure of the concrete containing waste vehicle tire”, Comput. Concr., 5(5), 503-508.

Emiroglu, M., Yildiz, S., Kelestemur, M.H. and Kelestemur, O. (2012), "Bond performance of rubber particles in the self-compacting concrete", Proceedings of the 4th International Symposium on Bond in Concrete 2012: Bond, Anchorage, Detailing, Brescia, Italy, 2012 Publisher creations.

Giner, V.T., Ivorra, S., Baeza, F.J., Zornoza, E. and Ferrer, B. (2011), "Silica fume admixture effect on the dynamic properties of concrete", Constr. Build. Mater., 25(8), 3272-3277.

Güneyisi, E., Gesoğlu, M. and Özturan, T. (2004), "Properties of rubberized concretes containing silica fume ", Cement Concrete Res., 34(12), 2309-2317.

Hassan, A.M.T. and Jones, S.W. (2012), "Non-destructive testing of ultra high performance fibre reinforced concrete (UHPFRC): A feasibility study for using ultrasonic and resonant frequency testing techniques", Constr. Build. Mater., 35, 361-367.

Khatib, Z.K. and Bayomy, F.M. (1999), "Rubberized portland cement concrete”, J. Mater. Civ. Eng., 11(3), 206-213.

Malhotra, V.M. (2006), Significance of Tests and Properties of Concrete and Concrete-making Materials, ASTM.

Malhotra, V.M. and Carino N.J. (2004), Handbook on Nondestructive Testing of Concrete, CRC Press.

Najim, K.B. and Hall, M.R. (2012), "Mechanical and dynamic properties of self-compacting crumb rubber modified concrete", Constr. Build. Mater., 27(1), 521-530.

Okamura, H. and Ouchi, M. (2003), "Self-Compacting Concrete", J. Advanced Concr. Tech., 1(1), 5-15.

Rahman, M.M., Usman, M. and Al-Ghalib, A.A. (2013), "Fundamental properties of rubber modified self-compacting concrete (RMSCC)", Constr. Build. Mater., 36, 630-637.

Topçu, I.B. (1995), “The properties of rubberized concretes”, Cement Concrete Res., 25(2), 304-310.

Turatsinze, A. and Garros, M. (2008), "On the modulus of elasticity and strain capacity of Self-Compacting Concrete incorporating rubber aggregates”, Resour. Conserv. Recy., 52(10), 1209-1215.

Zheng, L., Huo, X.S. and Yuan, Y. (2008), "Experimental investigation on dynamic properties of rubberized concrete", Constr. Build. Mater., 22(5), 939-947.

$C C$ 